\title{
Falls study: Proprioception, postural stability, and slips
}

\author{
Jeehoon Sohn ${ }^{\mathrm{a}}$ and Sukwon Kim ${ }^{\mathrm{b}, *}$ \\ ${ }^{a}$ Department of Physical Education, College of Cultural Industry, Arts, and Sports, Jeonju University, \\ Jeonju, South Korea \\ ${ }^{b}$ Department of Physical Education, College of Education, Research Institute of Physical Education, \\ Chonbuk National University, Jeonju, South Korea
}

\begin{abstract}
The present study evaluated effects of exercise training on the proprioception sensitivity, postural stability, and the likelihood of slip-induced falls. Eighteen older adults ( 6 in balance, 6 in weight, and 6 in control groups) participated in this study. Three groups met three times per week over the course of eight weeks. Ankle and knee proprioception sensitivities and postural stability were measured. Slip-induced events were introduced for all participants before and after training. The results indicated that, overall, strength and postural stability were improved only in the training group, although proprioception sensitivity was improved in all groups. Training for older adults resulted in decreased likelihood of slipinduced falls. The study suggested that proprioception can be improved by simply being active, however, the results suggested that training would aid older adults in reducing the likelihood of slip-induced falls.
\end{abstract}

Keywords: Training, proprioception, postural stability, slips, falls

\section{Introduction}

The joint proprioceptors are located in muscles and joints active in body movement and orientation in space $[1,2]$. The major class of receptors that provide information about position and movement are peripheral mechanoreceptors located in the joints, muscles, and skin. These mechanoreceptors provide motor programming with essential sensory information, allowing a person to accommodate unexpected perturbations or changes when visual information is not available [1,2]. For example, a person does not continuously examine information about the surface or condition of the floor when walking unless their eyes are continuously directed toward the walking surface; therefore, visual information in regard to a slippery surface may not be available at all times. In particular, proprioceptors in the joints were suggested to play a critical role in maintaining the functional stability of the joints [2-4]. Information from joint proprioceptive receptors is integrated into the motor programming required for precision movements and contributes to reflex muscle contraction, providing dynamic joint stability [1, 2, 5-8]. Proper sensorimotor control of lower extremities is critical to sustain mobility and intact joint stability [2,9-11]. For example, trainers suggested the

\footnotetext{
*Address for correspondence: Sukwon Kim, Department of Physical Education, College of Education, Research Institute of Physical Education, Chonbuk National University, Jeonju, South Korea. Tel.: 8263270 2860; Fax: 8263270 2850; E-mail: rockwall@jbnu.ac.kr.
} 
rehabilitation of proprioception in order to improve joint stability after an injury. Similar to an injured joint, an aging joint that does not possess a highly sensitive proprioceptive feedback system may not respond appropriately to variations in forces placed upon it during unexpected movements.

With advancing age, degradations in the proprioception threshold or sensitivity result in failure to sense changes in the displacement of the body mass [4, 12, 13]. Accordingly, older adults with diminished proprioception sensitivity may not be able to detect and correct postural disturbances as promptly as younger adults $[11,14]$. As a result, impaired postural stability [3, 4] and delayed responses to the perturbations [14-16] become apparent. Their inability to respond effectively to the balance perturbations, in turn, can result in unintentional falls resulting in permanent or fatal injuries to the hip, wrist, or head. An aging body exhibits decreased sensorimotor function in comparison to younger bodies $[10,15]$; older adults were unable to respond to postural perturbation such as slips in a timely manner, resulting in a pronounced increase in fall rates. In an effort to prevent falls and minimize such injuries, neuromuscular training has been suggested to help delay the deteriorations of proprioception, thus improving the effectiveness of somatosensory information on postural control [16-19]. The two main forms of exercises currently utilized to improve proprioception and postural stability are machine weight training and balance training [20-23]. While free weight training is precarious for older adults, machine weight training has commonly been suggested to be safer and easier [24]. The present study hypothesized that neuromuscular training would rehabilitate joint proprioception sensitivity of older adults, affecting the likelihood of slip-induced falls and postural stability among older adults.

\section{Method}

\subsection{Subjects}

The present study was approved by the Institutional Review Board. Prior to the experiments, the participants were informed verbally of study procedures, and provided informed written consent to participate. No participants possessed any known physical disorder to complicate the study; Physical Activity Readiness Questionnaire $(P A R-Q)$ was used as an initial screening tool. Eighteen older adults volunteers were randomly assigned to weight (age; 72.0 5.5 , height; $158.8 \pm 2.9$, weight; 69.4 \pm 5.3 ,

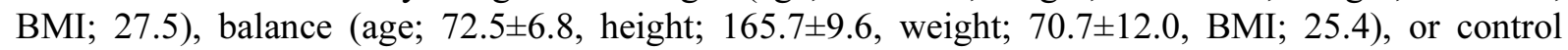
group (age; 76.5 \pm 8.3 , height; 161.5 \pm 9.9 , weight; 76.0 5.7 , BMI: 30.5). The three groups were equivalent in age $(p=0.48)$, height $(p=0.37)$, and weight $(p=0.41)$, though there was a subtle difference in BMI. Qualified participants for the present study had not participated in any form of exercise for 6 months prior to the study, or their current weight or balance exercise consisted of no more than thirty minutes per week. Any other form of exercise such as running, swimming, gardening, golf, etc. was not an exclusion criterion.

\subsection{Treatments}

Participants' daily activities were monitored throughout their participation in the study through daily interviews conducted by the experimenters and trainer. No participant engaged in any physical activities in addition to the exercises provided. Each group met three times per week over 8 weeks, each meeting lasting approximately one hour. The control group performed social activities (e.g. picnic, bingo, etc.); any activity that required physical performance was excluded with the exception 
Table 1

Weight Exercise Regimen

\begin{tabular}{|l|l|l|}
\hline Exercises & Target Muscle(s) & Synergist(s) \\
\hline Leg extension & Quadriceps & Gleuteus maximus, adductor magnus, soleus. \\
\hline Seated leg press & Quadriceps & Gluteus maximus, adductor magnus, and soleus \\
\hline Calf press & Gastrocnemius & Soleus \\
\hline Leg curl & Hamstring and & Gastrocnemius and sartorius \\
\hline $\begin{array}{l}\text { Hip abduction and } \\
\text { adduction }\end{array}$ & $\begin{array}{l}\text { Gluteus medius, minimus, andineus } \\
\text { maximus }\end{array}$ & Gluteus medius and minimus \\
\hline Hip extension & Gluteus maximus & Pections \\
\hline
\end{tabular}

Note: prioprioception testing protocols to measure participant recognition of a previously presented reference position [28-33].

of walking. Balance Training was performed on the floor during the first week to familiarize participants with the instructional manual of Stability Trainer [25]. For the following weeks, volunteers were trained on the green stability trainer (intermediate challenge level). Blue stability trainers (advanced challenge level) were introduced if an individual performed exercises perfectly and confidently on the green stability trainer; among six volunteers, only two progressed to perform the exercises on the blue stability trainer. Weight Training was performed in the NS-4000 home gym model (Nautilus ${ }^{\circledR}$, Vancouver, Washington 98684). Exercises mainly targeting lower extremities were developed (Table 1). Periodized strength training was employed because it was proven to be more effective in gaining strength than non-periodized strength training [26]. Two different hypertrophy phases were introduced for five weeks: three sets of ten repetitions at $50 \%$ maximum exertion for two weeks, and three sets of ten repetitions at $70 \%$ maximum exertion for three weeks. The strength phase encompassed the final three weeks, and consisted of three sets of seven repetitions at $85 \%$ maximum exertion. A 45-60 second resting period was observed between each set and a 150-190 second resting period was observed between exercises. Subjects performed 4-6 Repetition Maximum (RM) strength assessments for each exercise and determined 1 RM based on predicted values [27]. No upper body exercise was introduced.

\subsection{Testing and evaluation}

Two established methods to test proprioception are: 1) detection of movement and 2) recognition of a previously presented reference position. The present study adapted and applied previously published.

For the ankle proprioception test, participants were seated with their right foot on a footplate attached to Biodex System 3 (Biodex Medical Systems, Inc., Shirley, New York 11967). For the knee proprioception test, participants were seated with their right ankle strapped to a knee attachment and fixed to Biodex System 3. The subjects' ability to reproduce ankle and knee joint positions were tested once in each of two positions: $10^{\circ}$ plantarflexoin and $5^{\circ}$ dorsiflexion; both positions were identified to be least influenced by cutaneous sensory input in association with the extremes of the ROM [34]. Participants began in the common neutral position identified by experimenters. Each participant's right foot was placed on the footplate of the ankle attachment and rotated passively at the ankle joint in a direction of either plantarflexion or dorsiflexion. The ankle attachment was rotated at the speed of $1 \%$ second to either $10^{\circ}$ plantarflexion or $5^{\circ}$ dorsiflexion from the neutral start position. Ten seconds were given for participants to observe these positions before the ankle attachment was rotated back to the neutral position. Participants were asked to press a switch when they perceived the original 
position $\left(10^{\circ}\right.$ plantarflexion or $5^{\circ}$ dorsiflexion) while the ankle attachment was rotating at the speed of $1^{\circ} /$ second. For each trial, experimenters measured the difference in the angle between the original position $\left(10^{\circ}\right.$ plantarflexion or $5^{\circ}$ of dorsiflexion) and each attempt. For example, for a trial of $10^{\circ}$ plantarflexion, if a participant pressed the switch when reaching $8^{\circ}$ plantarflexion, the difference of $2^{\circ}$ was recorded to evaluate statistical significances. Three trials were collected with one-minute intervals, and were averaged for statistical testing.

For the knee proprioception test, the knee attachment was rotated from a neutral start position of $90^{\circ}$ knee flexion to allow extension at the knee joint. The knee attachment was rotated at the speed of $1 \%$ second and stopped at $15^{\circ}$ extension from the neutral start position. Ten seconds were given for participants to observe the position before the knee attachment was rotated back to the neutral position. Participants were asked to press a switch when they perceived the original position $\left(15^{\circ}\right.$ extension) while knee attachment was rotating at the speed of $1^{\circ} /$ second. The same technique was used to collect data for statistical testing.

Peak isokinetic ankle and knee strengths at $30 \%$ second, $90 \%$ second, and $120 \%$ second, as well as isometric ankle strengths at $15^{\circ}$ plantarflexion and isometric knee strengths at $15^{\circ}$ extension were evaluated using Biodex System 3. Starting positions were identical to the explanation in 2.3.1.

Center of Pressure (COP) was evaluated using a force platform (BERTEC \# K80102, TYPE 4555008, Bertec Corporation, OH 43212, USA) with the participants' eyes closed. In this study, multivariate analysis (factor analysis) was used to evaluate balance stability while standing quietly. Specifically, the eigenvalue-based descriptors in multivariate analysis were used to describe the variance of each factor ( $\mathrm{x}$ or $\mathrm{y}$ of COP); furthermore, ellipse areas were calculated using one eigenvalue as a long axis and the other eigenvalue as a short axis [35]. Stability was considered better if the calculated ellipse area was smaller, indicating smaller variance. In addition, COPdistance were calculated to evaluate the reaction mechanisms by the following formula:

\section{COPdistance $=X(i+1)-X(i)$, where $X=$ position of COP}

The average of the COP distance during 30 seconds of standing was parameterized.

Walking trials comprising the slipping and falling trials were conducted on a walking track $(20 \mathrm{~m})$, which was elevated $15 \mathrm{~cm}$ above the floor surface and consisting of vinyl tile [36]. The slippery surface was located $10 \mathrm{~m}$ from the deck end. Participants were instructed to look forward and walk straight at their preferred walking speed. Participants' cadence was measured within a subsequent 20minute session to ensure that their preferred walking speeds were consistent throughout the experiment. After ensuring that the preferred walking speeds were consistent, participants' natural posture and ground reaction forces were collected. While walking, participants were instructed to count colored circles in one of three different colors, flashed randomly and individually on a television screen located at each work station; this secondary task was provided to take away participants' attention from the floor surfaces. One of the main purposes of a walkway (during the slippery conditions) with two force plates embedded in the center (with sliding floor to switch from normal-dry floor surface to slippery floor surface) was to simulate real slip-induced fall events [36]. Some studies have simulated slip-induced fall events utilizing only 2-3 steps; in the present study, all walking trials lasted 15-20 minutes to better account for participants' natural gait characteristics, and the trial was terminated after the slippery surface was encountered. A fall arresting rig and safety harness was used to protect participants during the experiment, and was designed to permit participants to fall approximately $10 \mathrm{~cm}$ before arresting the falls and halting any forward motion. Slip distance, sliding 
heel velocity, COG velocity, and motion pictures were utilized to determine the fall frequency. To be considered a fall, the slip distance must exceed $10 \mathrm{~cm}$, and peak sliding heel velocity must exceed COG velocity while slipping [10]. Peak sliding heel velocity represented heel displacement and COG represented body position while slipping. Also, videos for each participant were analyzed to see if falls had occurred. All of the above three conditions had to be met in order to be considered as a fall. Identical procedures were performed before and after training. All participants wore identical shoes during pre- and post-training data collections to ensure that the RCOF was not influenced by differences in shoe sole.

\subsection{Data analysis}

Ground reaction forces were used to determine Center of Pressure (COP) for 30 seconds at $120 \mathrm{~Hz}$. The force data was filtered using fourth order zero-lag lowpass-Butterworth-filter at cut-off of $6 \mathrm{~Hz}$. Power analysis was performed to satisfy Type I error of 0.05 and Type II error of $<0.35$ (power $>0.65$ ). Power $(>0.65)$ was chosen as the acceptable power for analysis of a 6-week strength training regimen (Knight and Kamen, 2001; isometric strength difference between pre- and post-training $=176.8-136=$ $40.8 \mathrm{Nm}$ ). Potential threats to external validity may include the use of the lower statistical power (0.65). Training began immediately after the introductory meeting, with 24 initial participants. The study was evaluated with a mixed factor repeated measure design: $2 \times 3$ (time (pre and post training) $\times$ training (balance, weight, and control)). Training was a between-subjects factor and time was a within-subjects factor. The dependant measures, static balance stability, reaction time, isokinetic and isometric muscle strength, and proprioceptive sensitivity (joint position sensibility) were analyzed. Descriptive and inferential statistical analyses $(p \leq 0.05)$ were performed by utilizing the JMP statistical packages (SAS Institute Inc. Cary, NC, USA).

\section{Results}

\subsection{Effects on ankle and knee strength}

Right and left isokinetic extensor strengths improved after the 8-week training in both the balance training and the weight training groups in comparison to the control group, illustrated by the (TM $\times$ Time) interactions of all isokinetic extensor strengths in Table 2. Isokinetic flexor strengths and isometric strengths improved in all groups including the control group as illustrated by the (TM $\times$ Time) interaction in Tables 2 and 3. Right and left isokinetic extensor and flexor strengths, as well as isometric strengths improved in both the balance training and weight training groups in comparison to the control group, as illustrated by the (TM $\times$ Time) interactions in Tables 3 and 4 . Interestingly, the results in the interactions of left knee strength illustrated by (TM x Time) in Table 4 indicated that the control group also exhibited some improvement.

\subsection{Effects on proprioception sensitivity}

Proprioception sensitivity improved in all three groups after 8 weeks of training (Table 5). The results suggest that being socially active could result in the improvement of proprioception sensitivity in the ankle and knee. 
Table 2

Isokinetic ankle strength $(\mathrm{Nm})\left({ }^{*} \mathrm{TM}=\right.$ Training method, $\mathrm{R}=$ Right, $\mathrm{L}=$ Left, $\mathrm{Ex}=$ Extension, $\left.\mathrm{Fx}=\mathrm{Flexion}\right)$

\begin{tabular}{|c|c|c|c|c|c|c|}
\hline & & $\begin{array}{l}\text { Weight } \\
(\mathrm{N}=6)\end{array}$ & $\begin{array}{l}\text { Balance } \\
(\mathrm{N}=6)\end{array}$ & $\begin{array}{l}\text { Control } \\
(\mathrm{N}=6)\end{array}$ & $\begin{array}{l}\mathrm{P} \\
\text { (Time) }\end{array}$ & $\begin{array}{l}\text { P } \\
(\mathrm{TM} \\
\text { Time })\end{array}$ \\
\hline \multirow{2}{*}{ R $30 \mathrm{Ex}$} & Pre & $38.3 \pm 17.5$ & $34.5 \pm 8.5$ & $22.7 \pm 7.6$ & \multirow{2}{*}{0.003} & \multirow{2}{*}{0.003} \\
\hline & Post & $48.0 \pm 9.2$ & $45.7 \pm 12.1$ & $23.7 \pm 6.0$ & & \\
\hline \multirow{2}{*}{ R $30 \mathrm{Fx}$} & Pre & $8.2 \pm 2.6$ & $10.5 \pm 4.2$ & $7.2 \pm 3.4$ & \multirow{2}{*}{0.0003} & \multirow{2}{*}{0.15} \\
\hline & Post & $11.2 \pm 2.6$ & $11.5 \pm 5.1$ & $8.2 \pm 3.0$ & & \\
\hline \multirow{2}{*}{ R $90 \mathrm{Ex}$} & Pre & $27.3 \pm 17.3$ & $30 \pm 9.2$ & $17.5 \pm 6.9$ & \multirow{2}{*}{0.01} & \multirow{2}{*}{0.05} \\
\hline & Post & $40.2 \pm 8.1$ & $35.5 \pm 11.8$ & $17.0 \pm 4.3$ & & \\
\hline \multirow{2}{*}{ R $90 \mathrm{Fx}$} & Pre & $5.7 \pm 1.9$ & $6.3 \pm 3.3$ & $4.0 \pm 3.2$ & \multirow{2}{*}{0.01} & \multirow{2}{*}{0.94} \\
\hline & Post & $7.0 \pm 1.4$ & $6.3 \pm 2.9$ & $5.0 \pm 3.0$ & & \\
\hline \multirow{2}{*}{ R $120 \mathrm{Ex}$} & Pre & $25.7 \pm 16.0$ & $29.0 \pm 10.0$ & $16.7 \pm 6.6$ & \multirow{2}{*}{0.001} & \multirow{2}{*}{0.02} \\
\hline & Post & $35.0 \pm 8.0$ & $33.3 \pm 9.8$ & $16.7 \pm 5.2$ & & \\
\hline \multirow{2}{*}{ R $120 \mathrm{Fx}$} & Pre & $5.2 \pm 2.2$ & $4.5 \pm 3.4$ & $2.4 \pm 2.5$ & \multirow{2}{*}{0.004} & \multirow{2}{*}{0.76} \\
\hline & Post & $6.3 \pm 1.0$ & $5.0 \pm 3.0$ & $4.0 \pm 2.8$ & & \\
\hline \multirow{2}{*}{ L $30 \mathrm{Ex}$} & Pre & $35.3 \pm 9.6$ & $37.2 \pm 12.2$ & $24.3 \pm 6.9$ & \multirow{2}{*}{0.0006} & \multirow{2}{*}{0.07} \\
\hline & Post & $49.3 \pm 9.0$ & $45.0 \pm 12.0$ & $26.7 \pm 10.0$ & & \\
\hline \multirow{2}{*}{ L $30 \mathrm{Fx}$} & Pre & $9.0 \pm 4.0$ & $11.0 \pm 4.1$ & $8.5 \pm 7.3$ & \multirow{2}{*}{0.03} & \multirow{2}{*}{0.55} \\
\hline & Post & $11.0 \pm 3.8$ & $12.3 \pm 4.3$ & $9.0 \pm 4.7$ & & \\
\hline \multirow{2}{*}{ L $90 \mathrm{Ex}$} & Pre & $29.2 \pm 11.1$ & $27.3 \pm 12.1$ & $17.3 \pm 8.0$ & \multirow{2}{*}{0.0006} & \multirow{2}{*}{0.02} \\
\hline & Post & $38.5 \pm 10.9$ & $34.2 \pm 10.9$ & $17.3 \pm 6.7$ & & \\
\hline \multirow{2}{*}{ L $90 \mathrm{Fx}$} & Pre & $5.8 \pm 2.5$ & $6.2 \pm 3.1$ & $4.7 \pm 2.8$ & \multirow{2}{*}{0.0001} & \multirow{2}{*}{0.1} \\
\hline & Post & $7.7 \pm 3.9$ & $6.8 \pm 2.0$ & $5.3 \pm 2.9$ & & \\
\hline \multirow{2}{*}{ L $120 \mathrm{Ex}$} & Pre & $27.0 \pm 11.0$ & $26.5 \pm 12.3$ & $17.7 \pm 7.1$ & \multirow{2}{*}{0.002} & \multirow{2}{*}{0.0008} \\
\hline & Post & $34.7 \pm 9.3$ & $30.2 \pm 9.3$ & $18.5 \pm 6.3$ & & \\
\hline $\mathrm{I} 120 \mathrm{Fv}$ & Pre & $5.0 \pm 2.3$ & $5.0 \pm 3.4$ & $3.9 \pm 2.1$ & 0,0007 & $0-1$ \\
\hline L $120 \mathrm{Fx}$ & Post & $7.0 \pm 3.1$ & $5.3 \pm 2.1$ & $5.0 \pm 2.9$ & 0.0007 & 0.41 \\
\hline
\end{tabular}

Table 3

Isometric ankle and knee strength ( $\mathrm{Nm})$

\begin{tabular}{|c|c|c|c|c|c|c|}
\hline & & $\begin{array}{l}\text { Weight } \\
(\mathrm{N}=6)\end{array}$ & $\begin{array}{l}\text { Balance } \\
(\mathrm{N}=6)\end{array}$ & $\begin{array}{l}\text { Control } \\
(\mathrm{N}=6)\end{array}$ & $\begin{array}{l}\mathrm{P} \\
\text { (Time) }\end{array}$ & $\begin{array}{l}\text { P } \\
(\mathrm{TM} \\
\text { Time })\end{array}$ \\
\hline \multirow{2}{*}{$\begin{array}{l}\text { Ankle } \\
\text { R15 Ex }\end{array}$} & Pre & $52.2 \pm 18.9$ & $48.0 \pm 13.7$ & $31.8 \pm 9.2$ & \multirow{2}{*}{0.0021} & \multirow{2}{*}{0.28} \\
\hline & Post & $66.5 \pm 22.3$ & $59.8 \pm 17.5$ & $35.7 \pm 7.2$ & & \\
\hline \multirow{2}{*}{ R15 Fx } & Pre & $12.2 \pm 4.5$ & $14.8 \pm 4.3$ & $8.7 \pm 5.5$ & \multirow{2}{*}{0.02} & \multirow{2}{*}{0.08} \\
\hline & Post & $13.5 \pm 3.4$ & $16.5 \pm 6.9$ & $8.2 \pm 4.6$ & & \\
\hline \multirow{2}{*}{$\begin{array}{l}\text { Knee } \\
\text { R15 Ex }\end{array}$} & Pre & $75.5 \pm 18.7$ & $75.3 \pm 21.2$ & $65.0 \pm 11.9$ & \multirow{2}{*}{0.001} & \multirow{2}{*}{0.009} \\
\hline & Post & $94.5 \pm 15.7$ & $98.7 \pm 23.9$ & $61.8 \pm 11.2$ & & \\
\hline \multirow{2}{*}{$\mathrm{R} 15 \mathrm{Fx}$} & Pre & $34.3 \pm 12.4$ & $40.7 \pm 12.1$ & $31.2 \pm 7.5$ & \multirow{2}{*}{0.03} & \multirow{2}{*}{0.02} \\
\hline & Post & $40.3 \pm 12.0$ & $45.3 \pm 12.6$ & $28.8 \pm 7.8$ & & \\
\hline
\end{tabular}


Table 4

Isokinetic knee strength $(\mathrm{Nm})$

\begin{tabular}{|c|c|c|c|c|c|c|}
\hline & & $\begin{array}{l}\text { Weight } \\
(\mathrm{N}=6)\end{array}$ & $\begin{array}{l}\text { Balance } \\
(\mathrm{N}=6)\end{array}$ & $\begin{array}{l}\text { Control } \\
(\mathrm{N}=6)\end{array}$ & $\begin{array}{l}\mathrm{P} \\
\text { (Time) }\end{array}$ & $\begin{array}{l}\mathrm{P} \\
(\mathrm{TM} \times \text { Time }) \\
\end{array}$ \\
\hline \multirow[b]{2}{*}{ R 30 Ex } & Pre & $68 \pm 5.9$ & $63.7 \pm 12.7$ & $53.5 \pm 9.9$ & \multirow{2}{*}{0.001} & \multirow{2}{*}{0.001} \\
\hline & Post & $79.3 \pm 13.9$ & $73.3 \pm 18.8$ & $52.5 \pm 10.3$ & & \\
\hline \multirow{2}{*}{ R $30 \mathrm{Fx}$} & Pre & $41.7 \pm 6.7$ & $40.7 \pm 10.4$ & $32.8 \pm 6.8$ & \multirow{2}{*}{0.0001} & \multirow{2}{*}{0.05} \\
\hline & Post & $47.3 \pm 11.8$ & $45.3 \pm 11.0$ & $34.5 \pm 8.1$ & & \\
\hline \multirow{2}{*}{ R 90 Ex } & Pre & $52.3 \pm 7.0$ & $48.3 \pm 14.5$ & $40.7 \pm 8.7$ & \multirow{2}{*}{0.001} & \multirow{2}{*}{0.006} \\
\hline & Post & $59.5 \pm 7.6$ & $56.0 \pm 13.7$ & $38.8 \pm 10.8$ & & \\
\hline \multirow{2}{*}{ R $90 \mathrm{Fx}$} & Pre & $36.7 \pm 6.3$ & $37 \pm 12.4$ & $28 \pm 2.5$ & \multirow{2}{*}{$<0.0001$} & \multirow{2}{*}{0.001} \\
\hline & Post & $43.0 \pm 4.3$ & $43.5 \pm 11.0$ & $27.8 \pm 4.0$ & & \\
\hline \multirow{2}{*}{ R 120 Ex } & Pre & $47 \pm 7.6$ & $45.2 \pm 16.2$ & $36.2 \pm 6.9$ & \multirow{2}{*}{0.0001} & \multirow{2}{*}{0.0004} \\
\hline & Post & $53.5 \pm 8.1$ & $48.2 \pm 12.2$ & $34.3 \pm 7.2$ & & \\
\hline \multirow{2}{*}{ R $120 \mathrm{Fx}$} & Pre & $34.8 \pm 7.6$ & $36 \pm 13.6$ & $28.3 \pm 2.2$ & \multirow{2}{*}{0.0009} & \multirow{2}{*}{0.0013} \\
\hline & Post & $41.3 \pm 7.7$ & $42.2 \pm 11.1$ & $26.2 \pm 6.1$ & & \\
\hline \multirow{2}{*}{ L $30 \mathrm{Ex}$} & Pre & $57.8 \pm 9.8$ & $79.8 \pm 32.6$ & $40.8 \pm 3.1$ & \multirow{2}{*}{0.001} & \multirow{2}{*}{0.07} \\
\hline & Post & $75.5 \pm 14.4$ & $81.8 \pm 29.9$ & $44.2 \pm 7.7$ & & \\
\hline \multirow{2}{*}{ L $30 \mathrm{Fx}$} & Pre & $35.0 \pm 7.3$ & $46.7 \pm 18.3$ & $30.8 \pm 11.2$ & \multirow{2}{*}{$<0.0001$} & \multirow{2}{*}{0.0009} \\
\hline & Post & $49.5 \pm 8.9$ & $53.2 \pm 14.2$ & $30.0 \pm 8.9$ & & \\
\hline \multirow{2}{*}{ L $90 \mathrm{Ex}$} & Pre & $46.5 \pm 5.1$ & $55.0 \pm 27.5$ & $28.2 \pm 5.2$ & \multirow{2}{*}{0.0007} & \multirow{2}{*}{0.24} \\
\hline & Post & $55.7 \pm 9.9$ & $62.8 \pm 22.1$ & $31.3 \pm 4.5$ & & \\
\hline \multirow{2}{*}{ L $90 \mathrm{Fx}$} & Pre & $31.3 \pm 11.3$ & $36.3 \pm 16.0$ & $25.5 \pm 7.6$ & \multirow{2}{*}{0.0004} & \multirow{2}{*}{0.01} \\
\hline & Post & $43.0 \pm 9.0$ & $48.0 \pm 12.5$ & $25.5 \pm 5.5$ & & \\
\hline \multirow{2}{*}{ L 120 Ex } & Pre & $41.5 \pm 5.6$ & $48.7 \pm 22.6$ & $28.7 \pm 3.9$ & \multirow{2}{*}{0.005} & \multirow{2}{*}{0.09} \\
\hline & Post & $49.3 \pm 9.4$ & $55.5 \pm 19.5$ & $28.5 \pm 3.9$ & & \\
\hline & Pre & $32 \pm 5.1$ & $38.3 \pm 15.1$ & $25.7 \pm 7.1$ & & \\
\hline L 120 Fx & Post & $42.3 \pm 7.3$ & $46.0 \pm 12.4$ & $24.3 \pm 4.8$ & $<0.0001$ & 0.0001 \\
\hline
\end{tabular}

Table 5

Ankle (A) and Knee (K) Proprioception (degree) and Center of Pressure (COP) ( $\mathrm{mm}^{2}$ and $\mathrm{cm}$ )

\begin{tabular}{|c|c|c|c|c|c|c|}
\hline & & $\begin{array}{l}\text { Weight } \\
(\mathrm{N}=6)\end{array}$ & $\begin{array}{l}\text { Balance } \\
(\mathrm{N}=6)\end{array}$ & $\begin{array}{l}\text { Control } \\
(\mathrm{N}=6)\end{array}$ & $\begin{array}{l}\mathrm{P} \\
\text { (time) }\end{array}$ & $\begin{array}{l}\mathrm{P} \\
(\mathrm{TM} \times \mathrm{Time})\end{array}$ \\
\hline \multirow{2}{*}{$\begin{array}{l}\text { Proprioception }\left({ }^{\circ}\right) \\
\text { A Plantar } 10\end{array}$} & Pre & $3.4 \pm 1.3$ & $2.5 \pm 2.1$ & $4.2 \pm 3.1$ & \multirow{2}{*}{0.0004} & \multirow{2}{*}{0.54} \\
\hline & Post & $1.5 \pm 0.6$ & $0.5 \pm 0.1$ & $3.2 \pm 2.7$ & & \\
\hline \multirow{2}{*}{$\begin{array}{l}\text { Proprioception }\left(^{\circ}\right) \\
\text { A Dorsi } 5\end{array}$} & Pre & $0.9 \pm 0.4$ & $0.9 \pm 0.4$ & $2.6 \pm 1.8$ & \multirow{2}{*}{0.09} & \multirow{2}{*}{0.4} \\
\hline & Post & $0.7 \pm 0.3$ & $0.4 \pm 0.3$ & $2.6 \pm 1.7$ & & \\
\hline \multirow{2}{*}{$\begin{array}{l}\text { Proprioception }\left(^{\circ}\right) \\
\text { K Ex } 15\end{array}$} & Pre & $2.8 \pm 1.9$ & $3.8 \pm 3.1$ & $5.0 \pm 5.1$ & \multirow{2}{*}{0.002} & \multirow{2}{*}{0.1} \\
\hline & Post & $0.9 \pm 0.4$ & $2.3 \pm 2.3$ & $4.9 \pm 5.3$ & & \\
\hline \multirow{2}{*}{$\frac{\text { Center of Pressure }}{\text { Area }\left(\mathrm{mm}^{2}\right)}$} & Pre & $109.7 \pm 57.0$ & $166.2 \pm 167.2$ & $209.9 \pm 115.2$ & \multirow{2}{*}{0.0034} & \multirow{2}{*}{0.0227} \\
\hline & Post & $70.7 \pm 50.6$ & $70.7 \pm 80.7$ & $181.9 \pm 110.9$ & & \\
\hline \multirow{2}{*}{$\frac{\text { Center of Pressure }}{\text { Distance }(\mathrm{cm})}$} & Pre & $60.6 \pm 33.8$ & $76.2 \pm 39.9$ & $111.1 \pm 75.5$ & \multirow{2}{*}{0.0521} & \multirow{2}{*}{0.0123} \\
\hline & Post & $49.6 \pm 16.5$ & $55.4 \pm 27.5$ & $111.3 \pm 90.4$ & & \\
\hline
\end{tabular}

\subsection{Effects on postural stability}

COParea $\left(\mathrm{mm}^{2}\right)$ and COPdistance $(\mathrm{cm})$ in balance training and weight training groups exhibited a significant improvement in comparison to the control group (Table 4). These results may suggest that balance and weight training play a role in improving somatosensory, particularly in detecting perturbations. 


\subsection{Fall frequency}

Four individuals in each training group who fell in the pre-training stage recovered from slips in the post-training, and two individuals in each group who recovered from slips in the pre-training stage recovered from slips again in the post-training. In the control group, five individuals who fell in the pre-training stage fell again, and one individual who recovered from a slip again recovered. These results with consistent gait characteristics suggest that older individuals with training showed a greater ability to recover from slips.

\section{Discussion}

The objective of the present study was to evaluate if an 8-week balance or weight training program would be improve proprioception sensitivity or postural stability and reduce the likelihood of slipinduced falls. In the present study, after an 8-week training, the majority of individuals in training groups demonstrated improvement in ankle and knee isometric and isokinetic strengths [37-40] although the control group (social activity group) also showed slight ankle and knee improvement. Strength improvement in the control group was an interesting outcome in the present study because experimenters expected to see significant strength improvement in the balance and weight training social activity for older adults might also be beneficial [41-43]. The results also suggested that a reduction in strength with advancing age may not only be the result of physiological aging, but also, due to reduced social activity [41-43]. In order for the control group to socialize, they had to leave their residencies and, in many cases, were required to drive. Additionally, social activities often included walking in picnic areas, shopping malls, or museums. These kinds of activities were not a controlled physical training; however, these activities appear to have resulted in improved leg strength over 8 weeks. These results further indicated that older adults should be as active as possible to maintain their mobility.

Also, after 8 weeks, proprioception sensitivities for ankle plantarflexion and knee extension improved in all groups, including the control group. These results further indicated that being socially active could give appropriate stimulation for proprioceptive system and may attenuate this decline [33]. However, no statistical difference was observed in dorsiflexion proprioception sensitivity, likely due to the fact that the range of motion of dorsiflexion for the elderly was too small; $5^{\circ}$ dorsiflexion was almost the full extent of rotation toward the body for most of the participants in the present study, which may have affected proprioceptive sensitivity level in dorsiflexion. Authors would not recommend evaluating $5^{\circ}$ dorsiflexion for the elderly in future study. The results from the present study, however, indicated that postural stability improved in only training groups, and not in the control group. These results were somewhat surprising, because the strength and proprioceptive sensitivity improved in all groups including the control group (social activity group) after 8 weeks, whereas only individuals with formal weight or balance training exhibited improvements in postural stability. This may indicate that formal physical training is needed for the elderly to improve postural stability [37-40] although simply being active could be a factor in delaying degradations in strength as well as proprioceptive sensitivity.

For adequate postural stability, many different mechanisms are required to work simultaneously to keep the center of mass within the base of support. Integrations of the sensory system such as proprioceptive systems, skeletal muscle and central nervous system are particularly important; harmonious responses among the three systems are the major elements in maintaining stable upright 
posture $[10,20,21,28,30,44]$. Although social activities could play a role in improving strength and proprioceptive sensitivity at the ankle and knee joints, it does not enhance postural stability as much as formal physical training. The results from the present study suggested that only formal physical training could enhance integration of the three systems and increase postural control [37-40]. Diminished proprioception with aging may result in failure to sense changes in the displacement of the center of mass [13]. These results suggest that older adults may not be able to detect and correct postural disturbances as promptly as younger adults $[44,45]$. Particularly, these results from the studies above suggested that, due to the deteriorations in proprioception, the effectiveness of somatosensory information on postural control decreased with advancing age. These results suggested that there are positive effects of training on the likelihood of slips and falls. Overall, a decrease in the number of falls in training groups at post-stage evaluation in comparison to a same number of falls in the control group indicate the positive effects of training on fall rate. These results indicate that proprioception sensitivity, postural stability, and strength play a major role in reducing the likelihood of slip-induced falls.

In conclusion, postural stability, which required integration of the weight or balance-musculoskeletal systems, improved only in training groups. This indicated that only the formal exercise training enhanced the ability to integrate these three systems. Additionally, improvements in postural stability after training accounted for the reduction in the likelihood of slip-induced falls. Of course, the ability to integrate these systems played a critical role in recovering from dangerous slips. Older adults in either balance or weight training programs improved leg strength. Improvements in leg strength and its positive relationship to the likelihood of slip-induced falls indicated that the ability of leg muscles to produce explosive force at the ankle and knee joints while slipping contribute to reducing the likelihood of slip-induced falls. In addition, improvements in postural stability through training and its positive relationship to the likelihood of slip-induced falls indicated that an increased ability to integrate weight or balance-musculo-skeletal systems while slipping accounted for reducing the likelihood of slip-induced falls.

\section{Acknowledgement}

This paper was supported by research funds of Chonbuk National University in 2014.

\section{References}

[1] Z. Hasan and D. Stuart, Animal solutions to problems of movement control, Annual Review of Neuroscience 11 (1988), 199-223.

[2] B. Riemann and S. Lephart, The sensorimotor system, Part II: the role of proprioception in motor control and functional joint stability, Journal of Athletic Training 37 (2002), 80-84.

[3] A.A. Ahmed and J.A. Ashton-Miller, Is a "loss of balance" a control error signal anomaly? Evidence for three-sigma failure detection in young adults, Gait Posture 193 (2004), 252-262.

[4] A.A. Ahmed and J.A. Ashton-Miller, Effect of age on detecting a loss of balance in a seated whole-body balancing task, Clinical Biomechanics 20 (2005), 767-775.

[5] D. Goble, E. Hurvitz and S. Brown, Deficits in the ability to use proprioceptive feedback in children with hemiplegic cerebral palsy, International Journal of Rehabilitation Research 32 (2009), 267-269.

[6] F. Horak, L. Nashner and H. Diener, Postural strategies associated with somatosensory and vestibular loss, Experimental Brain Research 82 (1990), 167-177.

[7] J.T. Inglis, F.B. Horak, C.L. Shupert and C. Jones-Rycewicz, The importance of somatosensory information in triggering and scaling automatic postural responses in humans, Experimental Brain Reseach 101 (1994),159-164. 
[8] H. Johansson, P. Sjolander and P. Sojka, Receptors in the knee joint ligaments and their role in the biomechanics of the joint, Biomedical Engineering 18 (1991), 341-368.

[9] C.T. Leolard, The Neuroscience of Human Movement, Mosby-Year Book Inc., St Louis, MO, 1998.

[10] T.E. Lockhart, J.C. Woldstad, J.L. Smith and J.D. Ramsey, Effects of age related sensory degradation on perception of floor slipperiness and associated slip parameters, Safety Science 40 (2002), 689-703.

[11] Mansfield, P.Amy, L. Barbara and M. Brian, A perturbation-based balance training program for older adults: study protocol for a randomized controlled trial, BMC Geriatrics, 7 (2007), 12.

[12] M. Gilsing, G.C.Van den Bosch, S.G. Lee, et al., Association of age with the threshold for detecting ankle inversion and eversion in upright stance, Age Ageing 241 (1995), 58-66.

[13] D. Manchester, M. Wollacott, N. Zederbauer-Hylton and O. Marin, Visual, vestibular and somatosensory contributions to balance control in the older adult, Journal of Gerontology: Medical Sciences 44 (1989), M119-127.

[14] C.W. Luchies, D. Wallace, R. Pazdur, S. Young and A.J. DeYoung, Effects of age on balance assessment using voluntary and involuntary step tasks, Journal of Gerontology: Biological Science 543 (1999), M140-M144.

[15] B.E. Maki, W.E. Mcllroy and G.R. Fernie, Change-in-support reactions for balance recovery: control mechanisms, agerelated changes and implications for fall prevention, Engineering in Medicine and Biology Magazine 22 (2003), 20-26.

[16] L.D. Gillespie, W.J. Gillespie, M.C. Robertson, et al., Interventions for preventing falls in elderly people, Cochrane Database of Systematic Reviews 3 (2001), CD000340.

[17] Leroux, Exercise training to improve motor performance in chronic stroke: Effects of a community-based exercise program, International Journal of Rehabilitation Research 28 (2005), 17-23.

[18] S.R. Lord, S. Castell, J. Corcoran, et al., The effect of group exercise on physical functioning and falls in frail older people living in retirement villages: a randomized, controlled trial, Journal of the American Geriatrics Society 51 (2003), $1685-1692$.

[19] K.M Means, D.E. Rodell and P.S. O'Sullivan, Balance, mobility, and falls among community-dwelling elderly persons: effects of a rehabilitation exercise program, American Journal of Physical Medicine \& Rehabilitation 84 (2005), 238250.

[20] P. Aagaard, E.B. Simonsen, J.L. Andersen, et al., Increased rate of force development and neural drive of human skeletal muscle following resistance training, Journal of Applied Physiology 93 (2002), 1318-1326.

[21] P. Aagaard, E.B. Simonsen, J.L. Andersen, et al., Neural adaptation to resistance training: changes in evoked V-wave and H-reflex responses, Journal of Applied Physiology 92 (2002), 2309-2318.

[22] J. Judge, Balance training to maintain mobility and prevent disability, American Journal of Preventive Medicine 25 (2003), 150-156.

[23] M. Mador, B. Erkan, S. Mary and K. Thomas, Endurance and strength training in patients with COPD, Chest 125 (2004), 2036-2045.

[24] American College of Sports Medicine, Position stand: The recommended quantity and quality of exercise for eveloping and maintaining cardiorespiratory and muscular fitness and flexibility in healthy adults, Medicine and Science in Sports and Exercise 30 (1998), 975-991.

[25] http://www.thera-band.com/instructions.php and http://www.thera-band.com/store/products.php? Product ID=24, Last visit: September 21, 2013.

[26] D. Baker, G. Wilson and R. Carlyyon, Periodization: the effect on strength of manipulating volume and intensity, Journal of Strength and Conditional Research 8 (1994), 235-242.

[27] P. Dohoney, J. Chromiak, D. Lemire, B. Abadie and C. Kovacs, Prediction of one repetition maximum strength from a 4-6 RM and a 7-8 RM submaximal strength test in health young adults males, Journal of Exercise Physiology 5 (2002), 54-59.

[28] S. Fleck and W. Kraemer, Designing resistance training programs, Champaign: Human Kinetics, 1997.

[29] L.M. Koralewicz and G.A. Engh, Comparison of proprioception in arthritic and age-matched normal knees, The Journal of Bone and Joint Surgery 82 (2000), 582-88.

[30] D. Matre, A. Lars and K. Stein, Effects of localization and intensity of experimental muscle pain on ankle joint proprioception, European Journal of Pain 6 (2002), 245-260.

[31] K. Miura, I. Yasuyuki, T. Eiichi, O. Yoshihisa, O. Hironori and T. Satoshi, The effect of local and general fatigue on knee proprioception, The Journal of Arthroscopic and Related Surgery 20 (2004), 414-418.

[32] K. Refshauge, R. Chan, L. Janet and D.I. McCloskey, Detection of movements imposed on human hip, knee, and ankle and toe joints, Journal of Physiology 488 (1995), 231-241.

[33] R. Patrella, P. Lattanzio and M. Nelson, Effects of age and activity on knee joint proprioception, American Journal of Physical Medicine \& Rehabilitation 76 (1997), 235-241.

[34] N. Deshpande, D. Connelly, E. Culham and P. Costigan, Reliability and validity of ankle proprioceptive measures, Archives of Physical Medicine and Rehabilitation 84 (2003), 883-889. 
[35] M. Nussbaum, Postural Stability is compromised by fatiguing overhead work, American Industrial Hygiene Association Journal 64 (2003), 56-61.

[36] Sukwon Kim, T.E Lockhart and H. Yoon, Relationship between age-related gait adaptations and required coefficient of friction, Safety Science $\mathbf{4 3}$ (2005), 425-436.

[37] K. Swanik, S. Lephart, B. Swanik, S. Lephart, D. Stone, and F. Fu, The effects of shoulder plyometric training on proprioception and selected muscle performance characteristics, Journal of Shoulder and Elbow Surgery 11 (2002), 579-586.

[38] D. Fitzgerald, N. Trakarnratanakul, B. Smyth and B. Caulfield, Effects of a wobble board-based therapeutic exergaming system for balance training on dynamic postural stability and intrinsic motivation levels, The Journal of Orthopaedic \& Sports Physical Therapy 40 (2010), 11-19.

[39] M. Jan, P. Tang, J. Lin, S. Tseng, Y. Lin and D. Un, Efficacy of a target-matching foot-stepping exercise on proprioception and function in patient with knee osteoarthritis, Journal of Orthopaedic \& Sports Physical Therapy 38 (2006), 19-25.

[40] S. Hale, J. Hertel and L. Clmsted-Kramer, The effect of a 4-week comprehensive rehabilitation program on postural control and lower extremity function in individuals with chronic ankle instability, The Journal of Orthopaedic \& Sports Physical Therapy 37 (2007), 303-311

[41] M. Booth, N. Owen, A. Bauman, O. Clavisi and E. Leslie, Social-cognitive and perceived environment influences associated with physical activity in older Australians, Preventive Medicine 31 (2000), 15-22.

[42] De Bourdeaudhuij, P. Teixeira, G. Cardon and B. Deforche, Environmental and psychological correlates of physical activity in Portuguese and Belgian adults, Public Health Nutrition 8 (2005), 886-895.

[43] F. Reichert, A. Barros, M. Domingues and R. Hallal, The role of perceived personal barriers to engagement in leisuretime physical activity, American Journal of Public Health 97 (2007) 515-519.

[44] Kavounoudias, J.C. Gilhodes, R. Roll and J.P. Roll, From balance regulation to body orientation: Two goals for muscle proprioceptive information processing? Experimental Brain Research 124 (1999), 80-88.

[45] G.E. Stelmach and C.J. Worringham, Sensorimotor deficits related to postural stability: Implications for falling in the elderly, Clinics in Geriatric Medicine 1 (1985), 679-694. 